\title{
Remitting long-standing major depression in a multiple sclerosis patient with several concurrent conditions
}

This article was published in the following Dove Press journal:

Neuropsychiatric Disease and Treatment

\section{Navzer D Sachinvala' \\ Angeline Stergiou ${ }^{2}$ \\ Duane E Haines ${ }^{3,4}$}

'Retired, US Department of Agriculture-Agricultural Research Service, New Orleans, LA 70I24, USA; ${ }^{2}$ Department of Medicine, Fairfield Medical Center, Lancaster, $\mathrm{OH} 43130$, USA; ${ }^{3}$ Department of Neurobiology and Anatomy, Wake Forest School of Medicine, Winston-Salem, NC 27I57, USA; ${ }^{4}$ Department of Neurobiology and Anatomy, The University of Mississippi Medical Center, Jackson, MS 39216 , USA
Correspondence: Navzer D Sachinvala 226I Brighton Place, Harvey,

LA 70058, USA

Email sachinvala@aol.com
Abstract: In this report, we discuss the case of an multiple sclerosis (MS) patient, age 62, who learned to attain and sustain euthymia despite his ailments. He has Ehlers Danlos Syndrome (EDS), asthma, MS, urticaria, and major depression (MD). Despite thriving limitations, the patient is an accomplished scientist, who struggled for $>$ twelve years to emerge from being confined to bed and wheel chair with MS, to walking with crutches, scuba diving, writing manuscripts, and living a positive life. Through former educators, he reacquired problem-solving habits to study the literature on his illnesses; keep records; try new therapies; and use pharmaceutical, nutritional, physical, and psychological methods to attain euthymia. With this inculcation, years later, he discovered that dimethyl fumarate (DMF) suppressed inflammation, cramping, urticaria, and asthma; and the combination of bupropion, S-adenosylmethionine (SAMe), vitamin-D3 (vit-D3), yoga, and self-hypnosis relieved MD. Then, after a 14-month respite, the patient, discovered that he had adult onset craniopharyngioma: a benign, recurring, epithelial tumor that grows from vestigial embryonic tissue (Rathke's pouch) which formed the anterior pituitary. The tumor grows aggressively and causes surrounding tissue and function losses. It caused headaches, disorientation, bitemporal vision loss, among other problems. To emerge from this conundrum, the patient employed his relearned habits; the above antidepressant cocktail (bupropion, SAMe, and vit-D3); and with 30 fractionated stereotactic radiation treatments shrank his tumor and gained relief. This is a single case, and methods we discovered serendipitously may not work for other chronically ill patients. Consequently, we want to encourage such patients and their physicians to discuss their experiences in peer-reviewed domains so readers may acquire new perspectives that help individualize their care, and have productive contented lives.

Keywords: craniopharyngioma, euthymia, dimethyl fumarate, bupropion, S-adenosylmethionine, vitamin D3

\section{Dedication}

This manuscript is dedicated to Professors Lisa and Fereydoon D'Javadi, Pasteur Institute, Paris, on their retirement, and in memory of Professor Esmail Meisami, Department of Neuroscience, University of Illinois, Urbana Champaign.

\section{Introduction}

Treatment of major depression (MD, or major depressive disorder, MDD), concurrent with several chronic conditions, involves learning and experimentation before changes in thinking, behavior, deportment, self-discipline, medications, and nutritional supplements afford relief. MDD induces sadness, hopelessness, anger, isolation, and disables sufferers. It dysregulates sleep and hunger, destroys one's ability to thrive, and mars joys in the lives of sufferers, caregivers, family, and friends. MDD does remit, it has no cure 
yet, and its toll is second only to cardiac diseases. ${ }^{1}$ Herein, we explain the case of a patient and the methods he discovered to gain and sustain euthymia. Later, the same methods helped him emerge positive from adult onset craniopharyngioma with minimum losses. We hope this report will inspire physicians and patients with chronic conditions to publish their accounts in peer reviewed journals so much insight is available to help chronically ill patients manage themselves, their diseases, and live positive productive lives.

\section{The case}

This patient has battled MDD since childhood, and it appears that most of his conditions, including MDD arise from congenital hypermobility-type Ehlers Danlos Syndrome (EDS) (Figure 1A1 and A2). EDS describes $>$ ten connective tissue and enzyme disorders due to mutations in collagen, tenascin, and/or filamin-A gene families. ${ }^{3-5}$ EDS related signs seen in the patient include urticaria (Figure 1B1) and eczema (Figure 1B2); asthma; anemia; major depression (MD) indicated by ventricular enlargement ${ }^{2}$ depression inventories, ${ }^{1,3,4}$ and occipital lobe bending (OLB) ${ }^{6}$ (Figure 1C and G); unilateral periventricular heterotopia (Figure 1D) ${ }^{7}$ multiple allergies; nasal cartilage defects ${ }^{4,5}$ (Figure 1G); infections (difficult to resolve); ${ }^{4,5}$ and multiple sclerosis (MS) related corpus callosum lesions that hamper coordination of hands, and may portend cognitive decline (Figure 1E) ${ }^{8,9}$ Figure 1 also displays MRIs of conjoined craniopharyngiomas (Figure 1E and $\mathrm{F}$ ); and peaks representing fats and hydroxyl compounds in the MR-spectrum of the papillary cyst (MRS, Figure 1G). ${ }^{11}$ Collectively: the patient's symptoms (headaches and hemianopsia); his MRIs; his endocrine workup; plus characteristic magnetic resonance spectroscopy MRS peaks, only seen in papillary (soft, fluid filled) craniopharyngiomas aided the tentative craniopharyngioma diagnosis without performing a surgical biopsy. ${ }^{10-12}$ Craniopharyngiomas are considered benign brain tumors because their location and growth occur only in the perisellar region. However, they do recur within 3-10 years after removal through surgery and/or radiation and cause tissue and function losses when large and impinging on surrounding cerebral tissues. ${ }^{10-12}$

Owing to recurring asthma, respiratory tract and lung infections, urticaria, and multiple allergies to fish products, Bactrim $^{\circledR}$ (sulfamethoxazole/trimethoprim, morphine-based analgesics, etc.), at age 19, the patient was diagnosed selective immunoglobulin-M (IgM) deficient; ${ }^{13,14}$ and by mid-40s had lens replacements for premature cataracts; and three
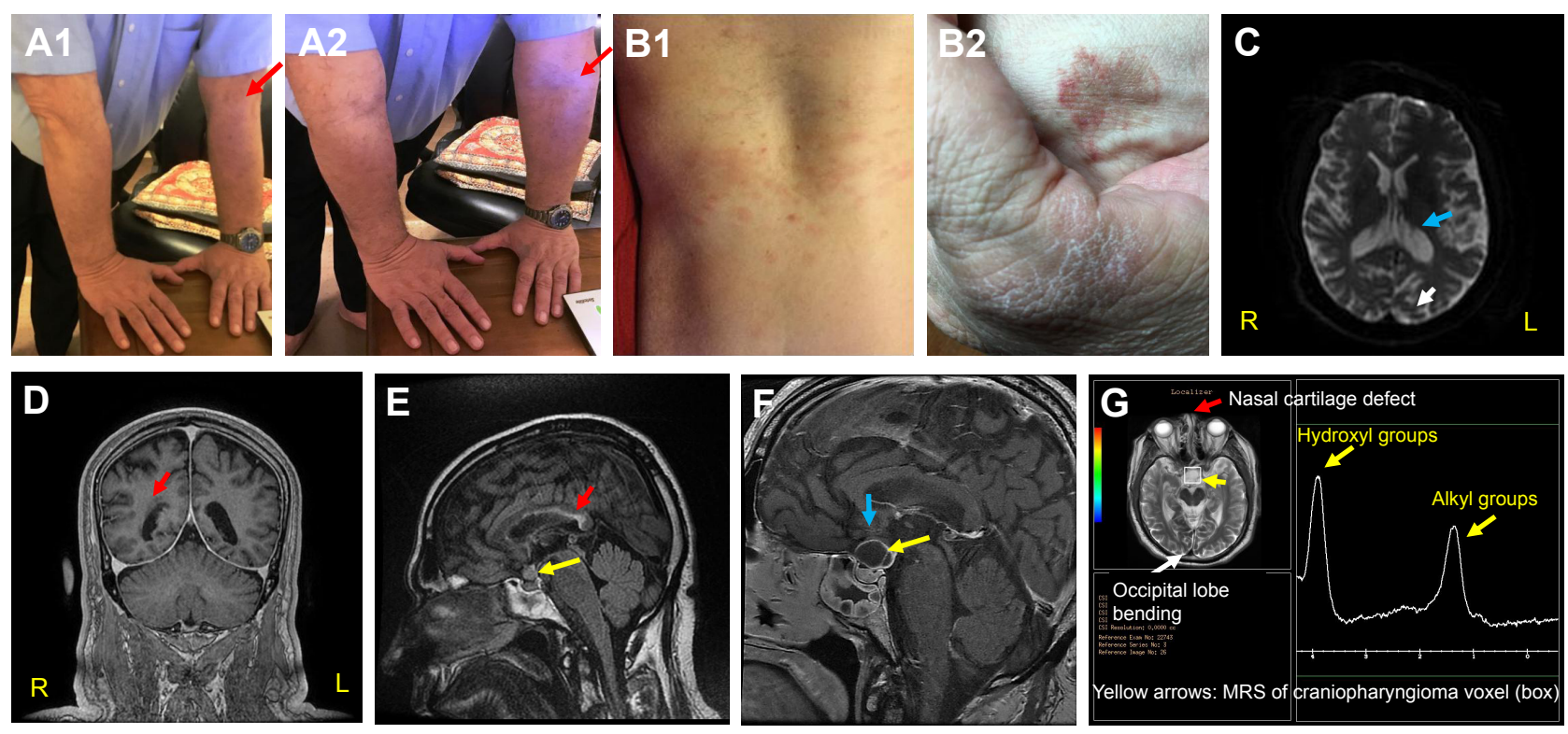

Figure I Signs observed in the current case.

Notes: (A I, A2) Congenital hyper-flexibility type EDS (red arrows, elbows); 4 (B I, B2) recurrent urticaria and eczema on torso (B I) and hands (B2); 4 (C) MS and MDDrelated ventricular enlargement and occipital lobe bending (OLB, blue and white arrows, respectively), ${ }^{1,2,6}$ OLB is also shown in (G). (D) EDS-related unilateral periventricular heterotopia (PH, red arrow), which supports the patient's dyslexia diagnosis.' (E) Red arrow, MS lesions along body and splenum of corpus callosum. They indicate difficulties in coordinating R/L hands and may portend cognitive decline. ${ }^{8.9}$ Yellow arrow - craniopharyngioma $\left(0.9 \mathrm{~cm}^{3}\right)$ comprising papillary (soft, anterior), and adamantinous (hard, posterior) cysts bound by a single epithelium. ${ }^{10-12}$ (F) Yellow arrow, conjoined craniopharyngioma cysts (soft $\sim 2.3 \mathrm{~cm}^{3}$ and hard $\sim 0.5 \mathrm{~cm}^{3}$ ). At this stage, the tumor pressed against his optic chiasm (thin gray arch above the cyst, blue arrow) and caused bitemporal hemianopsia (bilateral peripheral vision losses). ${ }^{10-12}$ (G) Red arrow, EDS-related nasal cartilage defect. ${ }^{4,5}$ White arrow, OLB. ${ }^{6}$ Yellow arrows, single voxel (box) MRS of papillary cyst showing characteristic alkyl fats and hydroxyl resonances at $\delta \cong I-2$ and 3.5-4.2 ppm, respectively. Other CNS metabolites are not seen in papillary craniopharyngioma tumors. These MR-spectral characteristics are only seen in papillary craniopharyngiomas. ${ }^{11,12}$ Adamantinous cysts do not display MR-spectral resonances. Note, in this case report the corresponding author (NDS) is the patient.

Abbreviations: EDS, Ehlers Danlos Syndrome; MS, multiple sclerosis; MDD, major depressive disorder; OLB, occipital lobe bending; R, right; L, left. 
rhinoplasties and uvula removal to correct rhinitis and apnea. Selective IgM deficiency now appears prominently on his medical charts because when overlooked, and intravenous antibiotics not used during surgeries, he suffered infections that took months to resolve with antibiotics.

The patient belongs to a closed Indo-Iranian minority, Zoroastrians, who for centuries enforced consanguineous relations, and many families produced children with congenital maladies, viz, EDS, glucose-6-phosphate dehydrogenase and phosphoglucomutase deficiencies, multiple sclerosis, and Parkinson's disease, to name a few. ${ }^{15,16}$ Furthermore, with regards to plausible environmental contributors to his illnesses: the patient worked for $30+$ years with hazardous chemicals, and participated in scuba-diving activities involving venomous marine organisms for his research. ${ }^{17,18}$

The patient grew up in and has a stable supportive family and enjoyed a productive career with scientific publications and patents in organic chemistry, immunochemistry, and polymer science (Research Gate and Justia list 53 peer reviewed papers and 16 US patents, respectively, by this author; https://www.researchgate.net/profile/Navzer Sachinvala2/publications and http://patents.justia.com/inventor/ navzer-d-sachinvala). ${ }^{17,18}$

At 49 (January 2005), the patient was diagnosed with fulminant multiple sclerosis, which left him immobile, and unable to balance, or coordinate his hands. Three years later, he accepted disability retirement because he could not tolerate hot environments, grip and manipulate small objects, and play his piano and guitar, activities he once enjoyed. His Beck depression inventory (BDI) scores then ( $\sim 30-40$ s), indicated severe depression (Box 1). 1,6,19,20

Soon after MS was diagnosed, the patient received e-mails from his former physiology and neuroscience Professor, Esmail Meisami, who was with him at the University of Tehran, 1977-1979. Meisami helped him: review physiology, neuroscience, and psychiatry concepts from current textbooks and journals; strengthen gestalt; note physical and emotional changes in him; record BDI scores (Box 1); ${ }^{19,20}$ and manage intercostal and cardiac sphincter cramps with diaphragmatic breathing. ${ }^{21}$ Like Meisami, other former teachers also suggested having consistent routines and using yoga, meditation, and self-hypnosis to manage pain, anger, and sleep. ${ }^{22-24}$

\section{Box I BDI score interpretation}

0-15 = Euthymia to mild mood disturbances with life's ups and downs; 16-20 = Mild to intermediate clinical depression; $21-30=$ Moderate depression; $31-40=$ Severe depression; . $40=$ Extreme depression.

Note: Data from Veauthier et al ${ }^{19}$ and Benedict et al. ${ }^{20}$
Between 2005 and 2006, the patient received plasmapheresis, Novantrone ${ }^{\circledR}$ (mitoxantrone), and 6-methylprednasolone to suppress immune reactions. Then to delay relapses, he received immune modulation therapies (2007-15): Rebif ${ }^{\circledR}$ (interferon-beta-1-alpha), Tysabri ${ }^{\circledR}$ (natalizumab), Copaxone $\AA$, and Tecfedera $\AA$ (dimethyl fumarate). ${ }^{25-27}$

Likewise, after much experimentation with antidepressants, Bupropion, ${ }^{27,28}$ and supplements S-adenosylmethionine (SAMe), ${ }^{29}$ and vit-D $3,{ }^{30}$ were discovered; and with all his other medications (Box 2), yoga, ${ }^{22}$ self-hypnosis, ${ }^{23,24}$ and gym exercises he curbed inflammation to enable sustained euthymia. ${ }^{31}$ To date, gym exercises relieve stress, build strength, and improve stamina; ${ }^{31}$ yoga helps with balance, proprioception, and calm focus on tasks; and self-hypnosis and visualization ease pain, goal attainment, and fulfillment. ${ }^{22-24}$

Side effects of MS treatments were vertigo; cramps; sleeplessness; type-2 diabetes; weight gain (from 195 to 295 lb in $\sim 18$ months) and anger with high-dose steroid treatments; alarming elevations in serum alanine and aspartic transaminases (ALT $>100$, and AST $>80$; normal range for both 10-40 IU/dL); NASH; seropositivity to the John Cunningham Virus (JCV, with Tysabri); vasovagal responses and anaphylaxis (with Copaxone ${ }^{\mathbb{R}}$ ); and reduction in $\mathrm{CD}^{+}$and $\mathrm{CD}^{+} \mathrm{T}$-cells (with DMF). ${ }^{25-27,32-34}$ Throughout, his BDI scores (20 to $>40$ ) indicated moderate to severe MD (Box 1). ${ }^{19,20}$

Remarkably, months after starting DMF in spring 2014, NDS noticed reductions in: intercostal cramps, asthma attacks, and NASH and urticaria symptoms. Side effects of DMF were fatigue, MD, and reduction in T-cell counts. By summer 2015, his CD4+ (helper) and $\mathrm{CD}^{+}$(suppressor) T-cell counts became unacceptable, ([normal values in parentheses $] \mathrm{CD}^{+}=298[300-1,400$ cells $/ \mu \mathrm{L}] ; \mathrm{CD}^{+}=32$

Box 2 The patient's/NDS's current medications and nutritional supplements (condition: medication, [daily dose and frequency])

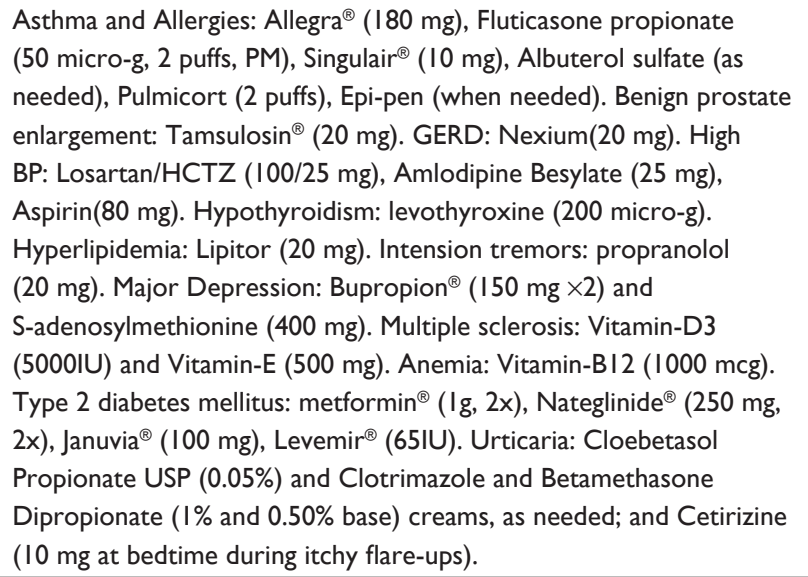

Asthma and Allergies: Allegra ${ }^{\circledR}(180 \mathrm{mg})$, Fluticasone propionate (50 micro-g, 2 puffs, PM), Singulair ${ }^{\circledR}$ (10 mg), Albuterol sulfate (as needed), Pulmicort (2 puffs), Epi-pen (when needed). Benign prostate enlargement: Tamsulosin ${ }^{\circledR}$ (20 mg). GERD: Nexium(20 mg). High $(25 \mathrm{mg})$ Aspirin(80 mg). Hypothyroidism: levothyroxine (200 micro-g). Hyperlipidemia: Lipitor (20 mg). Intension tremors: propranolol (20 mg). Major Depression: Bupropion ${ }^{\circledR}($ I50 mg $\times 2$ ) and S-adenosy Type 2 diabetes mellitus: metformin ${ }^{\circledR}(\mathrm{Ig}, 2 \mathrm{x})$, Nateglinide ${ }^{\circledR}(250 \mathrm{mg}$, $2 x)$, Januvia ${ }^{\circledR}$ (I00 mg), Levemir ${ }^{\circledR}$ (65IU). Urticaria: Cloebetasol Dipropionate ( $1 \%$ and $0.50 \%$ base) creams, as needed; and Cetirizine (10 mg at bedtime during itchy flare-ups). 
[200-900 cells $/ \mu \mathrm{L}] ; \mathrm{CD}^{+}: \mathrm{CD}^{+}$ratio $\left.=9.36[0.9-3.6]\right)$, and DMF was discontinued. ${ }^{25-27,32-34}$

Earlier, in January 2015, upon advisement from AS (coauthor), the patient started consuming SAMe (400 mg, daily), and by late summer 2015 witnessed AST and ALT values decline from $\sim 80$ and 100 to 13 and $37 \mathrm{IU} / \mathrm{dL}$, respectively. ${ }^{28,29}$ Furthermore, in summer that year, AS asked NDS to use vitamin-D3 (5,000 IU) to help with MDD, and it did (BDI $<15$ by December). ${ }^{20}$ So it appears that many changes enabled euthymia:

- Earlier immune suppression and modulation treatments: $;^{25-27}$

- Curbing painful MS-related cramps, and asthma, NASH, and urticaria symptoms with DMF; ;2,33

- Curbing inflammation and MDD with bupropion, SAMe, and vit-D3; ${ }^{29,30}$ and

- Keeping consistent routines for sleep, medications, etc. $22-24,31$

Thereafter, from late 2015 (November or December) to April 2017, the pateint enjoyed an affable and productive state of mind (BDI between 5 and 15) (Box 1). ${ }^{19,20} \mathrm{He}$ wrote manuscripts, and enjoyed scuba-diving trips to Florida , Hawaii, and the Caribbean.

In April 2017, he complained of blurry vision, headaches, and falling. His MRIs showed extant MS lesions, and a conjoined papillary and adamantinous tumor above the pituitary (combined volume $0.5 \mathrm{~cm}^{3}$ ). By December 2017, the papillary and adamantinous tumors grew to $2.3 \mathrm{~cm}^{3}$, and $0.5 \mathrm{~cm}^{3}$, respectively (Figure $1 \mathrm{E}$ and F). ${ }^{10}$ The abutted epithelial tumors were situated anterior to the hypothalamus; pressed against his optic chiasm from below; reduced his visual acuity (RS: from 20/20 and 20/40, to 20/70 and 20/100, respectively) and caused bitemporal visual field deficits, as well as left compressive optic nerve atrophy. However, his hypothalamic, pituitary, adrenal (HPA) axis and thyroid hormones remained within normal ranges. ${ }^{10-12}$

Adamantinous tumors, arise from CTNNB1 gene mutations that cause beta-catenin abnormalities as is seen in Rathke's cleft cysts, and hard craniopharyngiomas, but not in any other tumor in the peri-pituitary region. ${ }^{10,12}$ Papillary craniopharyngiomas arise from BRAF-MAPK signaling pathway anomalies, and their single voxel proton $\left({ }^{1} \mathrm{H}\right)$ spectra show characteristic alkyl resonances of fats (cholesterol, at $\delta 0.9-1.4 \mathrm{ppm}$ ) and hydroxyl groups (at $\delta 3.5-4.2 \mathrm{ppm}$ ). The patient's spectra matched published spectra of papillary craniopharyngioma (Figure 1G). ${ }^{11}$ Adamantinous tumors do not show MR-spectral resonances, and in MR-images they appear as white lesions. ${ }^{10-12}$

Collectively, his age, headaches, hemianopsia, all vision tests, endocrine workup results, and MRI and MRS data enabled a tentative craniopharyngioma finding without performing surgical biopsy. ${ }^{10-12}$ This is because many neurosurgeons then advised the pateint not to risk surgery due to his immune, MS, and EDS issues. Consequently, his tumor was destroyed with 30 fractionated stereotactic radiation treatments (FSRT). ${ }^{35,36}$

In March 2018, the patient had $R=20 / 25$ and $S=20 / 70$ vision; his coherence tomography showed left optic nerve atrophy, blurry central vision (scotoma) in the left eye; and his tumor had reduced $82 \%$ to $\sim 0.41 \mathrm{~cm}^{3} .35,36$ At present, he manages himself, walks a mile in $\sim 22$ minutes with crutches, runs on-spot multiple times a day with support to deal with narcolepsy, scuba-dives, and participates in writing and editing scientific review articles. His weight is 241 pounds (BMI 33.1), and weight management with episodic steroid use is a challenge.

\section{Discussion}

This patient suffers many EDS- and selective IgM deficiencyrelated problems, so we wanted to learn their interrelationships through the literature. We found that:

- While many immune and EDS problems may be transmitted genetically; ${ }^{1,3-6}$ inheriting selective IgM deficiency is unknown. ${ }^{13,14}$

- EDS and selective IgM deficiency are not reported to give rise to one another. However, sufferers of either ailment may have similar comorbidities: MS, allergies, susceptibility to infections, etc. ${ }^{1-3,6,13,14,31}$

- Common among such patients are inflammatory mechanisms, ie:

- Cytokines that provoke the conditions (eg, C-reactive protein, IFN-gamma, IL-1, IL-6, TNF-alpha, etc.);

- Chemokines that attract inflammatory cells to sites of inflammation (eg, CXC, CCL2, or monocyte chemoattractant protein-1, MCP-1, etc.); and

- Altered tryptophan metabolism, namely, over production and accumulation of kynurenic acid (KA, causes excitotoxicity); 3-hydroxylkyneurenine (3HK, free radically damages cells); and quinolinic acid (QA, causes neuron loss).

These changes are common among all inflammatory diseases: diabetes, cancer, MD, schizophrenia, etc. ${ }^{31}$ Fortunately, excess KA and metabolites are excreted from tissues, including the CNS, with physical exercises, which promote euthymia. ${ }^{1-4,31,32}$

\section{Conclusion}

Inflammatory maladies like MDD, MS, craniopharyngiomas, etc., are at present without cures and have huge 
disease burdens. Consequently, a mindset emerged in the patient to:

- Use yoga, self-hypnosis, and visualization to stay at peace within and attain goals, ${ }^{22-24}$

- Use over-the-counter medications when pain and helplessness are overwhelming;

- Soldier through side effects of prescribed therapies, noting effectiveness, and what stopped working after a while;

- Keep regular schedules for routines (sleep, exercise, etc.); and

- Tenaciously work to transcend disease-induced limitations by healthful means.

The above require rigorously studying current texts and science literature to find methods that accrue health benefits and improve mood, alertness, and physical and cognitive functioning.

We hope for all chronically ill patients, healing becomes an all-consuming puzzle to solve without giving-in to misery, or seeking untimely exit. This patient derives much joy and fulfillment by researching and finding new solutions to problems. Having said this, we realize, that methods and attitudes we discussed may not work for all patients; so, we want to read and learn new approaches to euthymia from patients and physicians who treat the chronically ill.

\section{Acknowledgments}

We thank Professors Bin Teh, Armen Kocharian, Steve Fung, and David Baskin, Radiation Oncology, Radiology, and Neurosurgery Departments, Houston Methodist Hospital for managing NS's craniopharyngioma and associated problems; Professors Keki and Mazda Turel, Department of Neurosurgery, Bombay University for helpful discussions on endocrine and anatomic changes in MS, MDD, and craniopharyngioma; Dr James G Nadeau, US Food and Drug Administration, Silver Springs, MD; and Professor Naozumi Teramoto, Chiba Institute of Technology, Chiba, Japan for references, many insightful discussions, and editing and improving the quality of our manuscript.

\section{Author contributions}

Using his clinical records, NDS wrote and edited the entire manuscript. After reviewing his clinical records, coauthor AS focused NDS's attention (between 2013 and 2015) on inflammatory triggers to help him manage MDD and helped with early editing. DEH was invited as coauthor because of his knowledge in neuroscience. He edited the first draft. All authors contributed toward analysis of the case and its clinical data; drafting and revising the paper; and all agree to be accountable for all aspects of this work.

\section{Disclosure}

The authors report no conflicts of interest in this work.

\section{References}

1. O'Reardon JP, Amsterdam JD. Medical Disorders and Treatment Resistant Depression, in Treatment Resistant Mood Disorders. Amsterdam JD, editor. UK: Cambridge University Press; 2007:405-429.

2. Scott ML, Golden CJ, Ruedrich SL, Bishop RJ. Ventricular enlargement in major depression. Psychiatry Res. 1983;8(2):91-93.

3. Hershenfeld SA, Wasim S, McNiven V, et al. Psychiatric disorders in Ehlers-Danlos syndrome are frequent, diverse and strongly associated with pain. Rheumatol Int. 2016;36(3):341-348.

4. Kumar V, Abbas AK, Aster JC. Ehlers Danlos Syndrome, in Chapter 5, Genetic Disorders; in Robbins and Cotran, Pathologic Basis of Disease. 9th ed. Philadelphia, PA: Elsevier; 2015:137-183; 145-146.

5. Genetics Home Reference. Ehlers-Danlos syndrome. Available from: https:/ghr.nlm.nih.gov/condition/ehlers-danlos-syndrome\#genes. Accessed September 12, 2018.

6. Maller JJ, Thomson RH, Rosenfeld JV, Anderson R, Daskalakis ZJ, Fitzgerald PB. Occipital bending in depression. Brain. 2014;137 (Pt 6):1830-1837.

7. Sheen VL, Walsh CA. Periventricular heterotopia: new insights into Ehlers-Danlos syndrome. Clin Med Res. 2005;3(4):229-233.

8. Dogonowski AM, Andersen KW, Madsen KH, et al. Multiple sclerosis impairs regional functional connectivity in the cerebellum. Neuroimage Clin. 2014;4:130-138.

9. Jongen PJ, Ter Horst AT, Brands AM. Cognitive impairment in multiple sclerosis. Minerva Med. 2012;103(2):73-96.

10. Osborn AG, Salzman KL, Jhaveri MD (editors). Craniopharyngioma, in Diagnostic imaging. Brain. 3rd ed. Philadelphia, PA: Elsevier; 2016:1048-1051.

11. Einstien A, Virani RA. Clinical Relevance of Single-Voxel (1)H MRS Metabolites in Discriminating Suprasellar Tumors. J Clin Diagn Res. 2016;10(7):TC01-TC04.

12. Saeger W. New aspects of tumor pathology of the pituitary. Pathologe. 2015;36(3):293-300.

13. Gupta S, Gupta A. Selective IgM Deficiency - An Underestimated Primary Immunodeficiency. Front Immunol. 2017;8:1056.

14. National Center for Advancing Translational Sciences [webpage on the Internet]. Selective immunoglobulin M deficiency; SIgMD. Available from: https://rarediseases.info.nih.gov/diseases/12547/selective-igmdeficiency. Accessed September 12, 2018.

15. López S, Thomas MG, van Dorp L, et al. The Genetic Legacy of Zoroastrianism in Iran and India: Insights into Population Structure, Gene Flow, and Selection. Am J Hum Genet. 2017;101(3):353-368.

16. Kariminejad A, Bozorgmehr B, Khatami A, Kariminejad MH, Giunta C, Steinmann B. Ehlers-Danlos Syndrome Type VI in a 17-Year-Old Iranian Boy with Severe Muscular Weakness - A Diagnostic Challenge? Iran J Pediatr. 2010;20(3):358-362.

17. Bignami GS, Raybould TJ, Sachinvala ND, et al. Monoclonal antibodybased enzyme-linked immunoassays for the measurement of palytoxin in biological samples. Toxicon. 1992;30(7):687-700.

18. Sachinvala ND [webpage on the Internet]. Tetrodotoxin immunoassays, Phases 1 \& 2. Available from: https:/www.sbir.gov/sbirsearch/ detail/179668 and https://www.sbir.gov/sbirsearch/detail/179842. Accessed September 12, 2018.

19. Veauthier C, Gaede G, Radbruch H, Wernecke KD, Paul F. Poor Sleep in Multiple Sclerosis Correlates with Beck Depression Inventory Values, but Not with Polysomnographic Data. Sleep Disord. 2016;2016:8378423.

20. Benedict RH, Fishman I, McClellan MM, Bakshi R, WeinstockGuttman B. Validity of the Beck Depression Inventory-Fast Screen in multiple sclerosis. Mult Scler. 2003;9(4):393-396.

21. Chen YF, Huang XY, Chien CH, Cheng JF. The Effectiveness of Diaphragmatic Breathing Relaxation Training for Reducing Anxiety. Perspect Psychiatr Care. 2017;53(4):329-336. 
22. Cramer H, Lauche R, Langhorst J, Dobos G. Yoga for depression: a systematic review and meta-analysis. Depress Anxiety. 2013;30(11): 1068-1083.

23. Tiers M. Integrative Hypnosis a Comprehensive Course in Change. New York: Melissa Tiers Publisher; 2010.

24. Bandler R, Grinder J. Patterns of the hypnotic techniques of Milton Erickson, MD, Volume 1, Cupertino, CA: Meta Publications; 1975.

25. Gwathmey K, Balogun RA, Burns T. Neurologic indications for therapeutic plasma exchange: an update. J Clin Apher. 2011;26(5):261-268.

26. Kamm CP, Uitdehaag BM, Polman CH. Multiple sclerosis: current knowledge and future outlook. Eur Neurol. 2014;72(3-4):132-141.

27. Fernández Ó. Future challenges in multiple sclerosis. Med Clin (Barc). 2014;143(Suppl 3):44-47.

28. Pardini M, Capello E, Krueger F, Mancardi G, Uccelli A. Reward responsiveness and fatigue in multiple sclerosis. Mult Scler. 2013;19(2): 233-240.

29. Triantafyllou N, Evangelopoulos ME, Kimiskidis VK, et al. Increased plasma homocysteine levels in patients with multiple sclerosis and depression. Ann Gen Psychiatry. 2008;7:17.

30. Røsjø E, Steffensen LH, Jørgensen L, et al. Vitamin D supplementation and systemic inflammation in relapsing-remitting multiple sclerosis. J Neurol. 2015;262(12):2713-2721.
31. Cervenka I, Agudelo LZ, Ruas JL. Kynurenines: Tryptophan's metabolites in exercise, inflammation, and mental health. Science. 2017; 357(6349):eaaf9794.

32. Bartsch T, Rempe T, Wrede A, et al. Progressive neurologic dysfunction in a psoriasis patient treated with dimethyl fumarate. Ann Neurol. 2015;78(4):501-514.

33. Longbrake EE, Cantoni C, Chahin S, Cignarella F, Cross AH, Piccio L. Dimethyl fumarate induces changes in B- and T-lymphocyte function independent of the effects on absolute lymphocyte count. Mult Scler. 2018;24(6):728-738.

34. Chaves C, Ganguly R, Ceresia C, Camac A. Lymphocyte subtypes in relapsing-remitting multiple sclerosis patients treated with dimethyl fumarate. Mult Scler J Exp Transl Clin. 2017;3(2):205521731770293.

35. Barber SM, Teh BS, Baskin DS. Fractionated Stereotactic Radiotherapy for Pituitary Adenomas: Single-Center Experience in 75 Consecutive Patients. Neurosurgery. 2016;79(3):406-417.

36. Hasegawa T, Kobayashi T, Kida Y. Tolerance of the optic apparatus in single-fraction irradiation using stereotactic radiosurgery: evaluation in 100 patients with craniopharyngioma. Neurosurgery. 2010; 66(4):688-694; discussion 694-695.
Neuropsychiatric Disease and Treatment

\section{Publish your work in this journal}

Neuropsychiatric Disease and Treatment is an international, peerreviewed journal of clinical therapeutics and pharmacology focusing on concise rapid reporting of clinical or pre-clinical studies on a range of neuropsychiatric and neurological disorders. This journal is indexed on PubMed Central, the 'PsycINFO' database and CAS,

\section{Dovepress}

and is the official journal of The International Neuropsychiatric Association (INA). The manuscript management system is completely online and includes a very quick and fair peer-review system, which is all easy to use. Visit http://www.dovepress.com/testimonials.php to read real quotes from published authors. 